$\xi=-1$

\title{
Modelling and simulation of ZDC controlled PMSG based wind energy conversion system
}

\author{
Tripura Pidikiti ${ }^{1 *}$, Tulasi Ram Das $\mathbf{G}^{2}$ \\ ${ }^{1}$ Assistant Professor of EEE, K L Education Foundation, Vijayawada and India \\ ${ }^{2}$ Professor of EEE, JNTU College of Engineering Hyderabad and India \\ *Corresponding author E-mail: tripura.pidikiti@gmail.com
}

\begin{abstract}
This paper presents the comparison of dynamic performance and steady state operation of PMSG wind energy conversion systems with two modulation techniques. Voltage oriented control (VOC) is used for grid-connected converter along with sinusoidal pulse width modulation (SPWM) and Space Vector Modulation (SVM) schemes. The generator is controlled by using zero d- axis current (ZDC) control scheme along with optimal torque control (OTC). Performance comparison with two pulse width modulation schemes through simulation results are presented for 2MW/ 690V/ 9.75Hz Non-Salient Pole PMSG using MATLAB/SIMULINK.
\end{abstract}

Keywords: Permanent Magnet Synchronous Generator (PMSG); Sinusoidal Pulse Width Modulation (SPWM); Space Vector Modulation (SVM); Voltage Oriented Control (VOC); Wind Energy Conversion Systems (WECS).

\section{Introduction}

Due to exhausting fossil fuels, raise in cost and global warming, renewable energy sources have turned up as a new criterion to fulfill the energy needs of our society [6]. The electricity generation from the hydro, wind, geothermal, solar, tidal, biomass and wave energy sources are drawing more attention these days [11].In the meantime, advancements in the technology, reduction in the cost, and governmental encouragements have made some renewable energy sources more economical in the market. Among them, one of the fastest growing renewable energy sources is wind energy [4].

The two main electrical components of the WECS are power converter and generator. Various schemes of these two components show the way to a broad variety of WECS configurations, which can be classified into three groups: (1) fixed-speed WECS without power converter interface, (2) WECS using reduced-capacity converters, and (3) full-capacity converter operated WECS [3].Amongst the prevailing WECSs, its generators are classified into four types [2]: the doubly fed induction generator(DFIG), the squirrel cage induction generator(SCIG), the wound rotor synchronous generator(WRSG) and the PMSG. These days, the WECS with PMSG is used for direct grid- connection because it has no slip ring maintenance and gives higher efficiency. Thus, the low maintenance and lightweight characters can be acquired in this kind of WECS [5].

The generator control is carried out with ZDC to achieve linearity between generator torque and stator current relationship [8]. ZDC control provides an efficient solution and exceptional generator incorporation performance such as control algorithm which is simple, producing high efficiency, and decreasing loses of the system [9-10]. Still, the major problem with ZDC control is unsuitable for salient-pole synchronous generators as optimal operation cannot be achieved with ids=0 [1] [7].
VOC is used to control the grid side inverter. This technique is based on transformation among d-q synchronous frame and abc stationary reference frame. The control procedure is executed in the synchronous reference frame of grid voltage, while completely the variables are of DC in steady state and this helps in the control and design of the inverter.

The key objectives of paper are to implement the VOC with a decoupling controller for the grid-connected converter; to design sinusoidal pulse width modulation and space vector modulation schemes for grid- and generator-connected converters; and finally to implement ZDC control scheme for full-scale power converter based variable-speed, direct-drive non-salient PMSG WECS.

\section{System description}

The configuration of the PMSG WECS with back-to-back converters is shown in fig 1 . Here PMSG converts wind turbine mechanical power into AC electrical power; it is again converted to DC with a converter with dc link supplying either the inverter connected to a grid or the load in case of stand-alone. With this inverter, ac electrical power with constant frequency and voltage is supplied to the power grid by PMSG. The generator side converter control and the grid side converter control schemes are presented in the subsequent sections. 


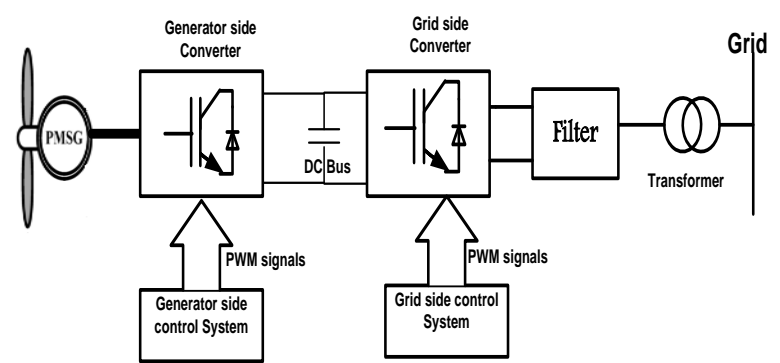

Fig. 1: PMSG Wind Energy Conversion System with Back to Back Converters.

\subsection{PMSG modelling}

The generator is normally modeled in the synchronous reference frame of rotor field. The generator voltage equations are given by

$v_{d s}=-R_{s} i_{d s}-\omega_{r} \lambda_{q s}+p \lambda_{d s}$

$v_{q s}=-R_{s} i_{q s}+\omega_{r} \lambda_{d s}+p \lambda_{q s}$

Where $\lambda_{q s}$ and $\lambda_{d s}$ are the q-axis and $\mathrm{d}$ - axis flux linkages of stator, given by

$\lambda_{d s}=-L_{d} i_{d s}+\lambda_{r}$

$\lambda_{q s}=-L_{q} i_{q}$

Where $\lambda_{r}$ is the rotor $\mathrm{d}$ axis flux due to permanent magnet, $\mathrm{L}_{\mathrm{d}}$ and $\mathrm{L}_{\mathrm{q}}$ are stator $\mathrm{d}$ and $\mathrm{q}$ - axis self-inductances. Substituting (3), (4) in (1), (2) and for constant field current $I_{f}$, we have

$v_{d s}=-R_{s} i_{d s}+\omega_{r} L_{q} i_{q s}-L_{d} p i_{d s}$

$v_{q s}=-R_{s} i_{q s}-\omega_{r} L_{d} i_{d s}+\omega_{r} \lambda_{r}-L_{q} p i_{q s}$

(6) $i_{s}=i_{q s}$

Based on the above equations, the simplified model of the PMSG is shown in Figure2. The electromagnetic torque can be calculated by

$T_{e}=\frac{3 P}{2}\left[i_{q s} \lambda_{r}-\left(L_{d}-L_{q}\right) i_{q s} i_{d s}\right]$

Where $\mathrm{P}$ is the pole pairs

(A) D-Axis Circuit

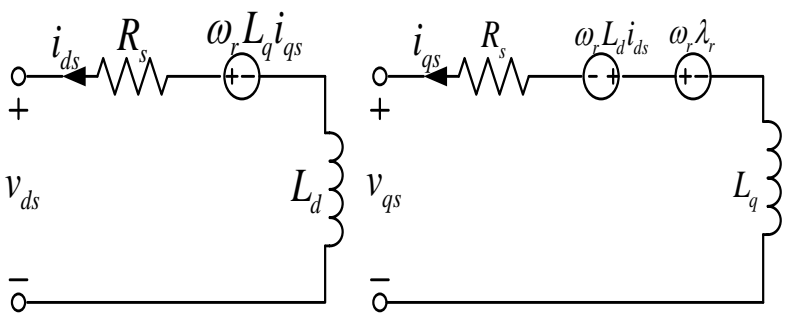

Fig. 2: Simplified DQ-Axis Model of PMSG in the Rotor-Field Synchronous Reference Frame.

\section{Optimal torque control (OTC)}

Generator is operated below the rated wind speed by controlling variable speed wind turbine. The fundamental objective is to maximize the power capture at variable wind speeds; this is achieved by adjusting turbine speed to keep the tip speed ratio constant. The trajectory of maximum power points represents a power curve which can be described by

$P_{M} \propto \omega_{M}^{3}$

Power captured by turbine is expressed in terms of torque as,

$P_{M}=T_{M} \omega_{M}$

Where $T_{M}$ is the turbine mechanical torque. From (8) \& (9)

$T_{M} \propto \omega_{M}^{2}$

MPPT (Maximum Power Point Tracking) scheme, with OTC is realized by computing the desired torque reference $T_{e}^{*}$. The optimal torque coefficient $\left(K_{\text {opt }}\right)$ is calculated from the turbine rated parameters. Wind speed sensors are not required in this scheme.

\subsection{Text font of entire document}

The entire document should be in Times New Roman. The font sizes to be used are specified in Table 1 .

\section{Generator side converter control}

All title and the generator side converter control arrangement is shown in Figure 3. ZDC and MPPT controls are employed for the generator side converter. The MPPT is achieved by generating generator torque reference $T_{e}^{*}$ using measured generator speed $\omega_{m}$.

The ZDC control is realized by resolving the three phase stator current in the stationary reference frame to $\mathrm{d}$ and $\mathrm{q}$ axis components in the synchronous frame at grid frequency. The d- axis component $i_{d s}$ is kept at zero [6]. With direct axis current equal to zero, the stator current becomes equal to q-axis current $i_{q s}$.

Where $i_{s}$, is the space vector of stator current. With zero d- axis current the torque equation (7) becomes

$T_{e}=\frac{3 P}{2}\left[i_{s} \lambda_{r}\right]$

From the above equation it is clear that, the generated torque is directly proportional to stator current $i_{s}$. The reference torque $T_{e}^{*}$ is generated from MPPT controller and torque producing component $i_{q s}^{*}$ is calculated from (12)

$i_{q s}^{*}=\frac{2 T_{e}^{*}}{3 P \lambda_{r}}$

The position angle of rotor flux $\theta_{r}$ is to be sensed for rotor flux field orientation. Three phase currents are measured and are then transformed into $i_{d s}$ and $i_{q s}$ using abc/dq transformation. These currents are compared with $i_{d s}^{*}$ and $i_{q s}^{*}$ and the corresponding errors are processed by the controllers to generate $v_{d s}^{*}$ and $v_{q s}^{*}$ for the rectifier. These voltages are converted to three phase reference voltages using dq/abc transformation. Generator Active power is controlled by controlling the rectifier using PWM technique. 


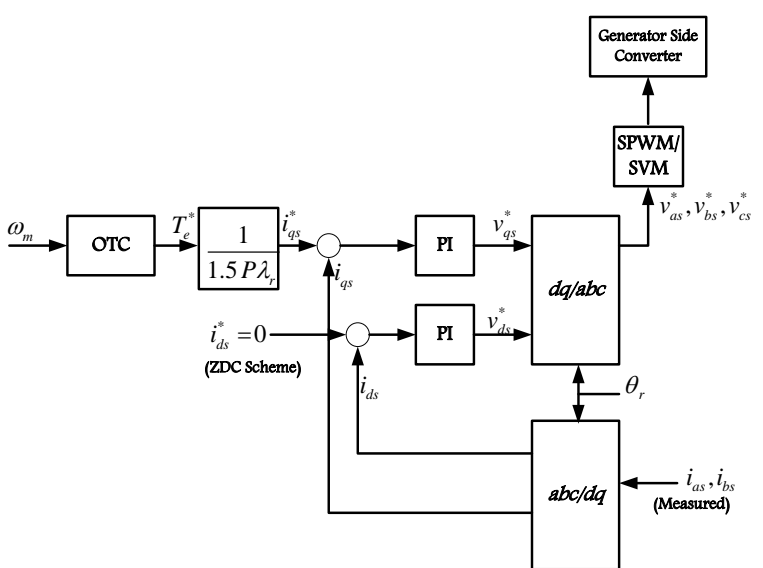

Fig. 3: Generator Side Converter Control Scheme.

\section{Control of the grid side converter (inverter)}

The main function of grid side converter is to control the reactive power and the DC link voltage $v_{d c}$. Grid voltage vector is tracked and the angle $\theta_{g}$ is generated by phase locked loop. This angle and grid voltage is used for the VOC of the grid side inverter. The block diagram of grid side converter control scheme is shown in Figure4.

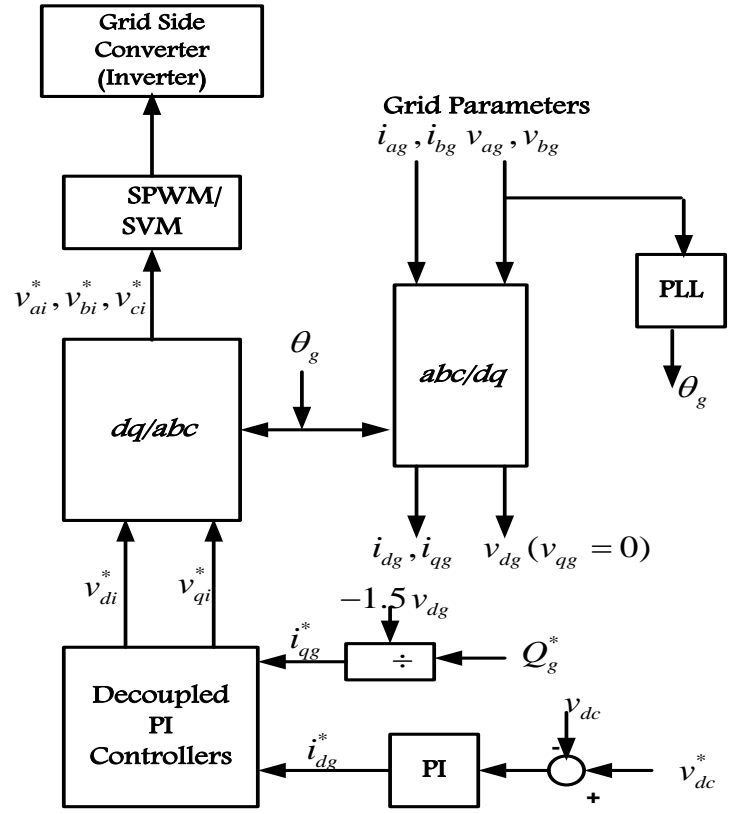

Fig. 4: Grid Side Converter Control Scheme.

Three feedback control loops are present in VOC scheme: one outer feedback loop to control DC voltage $v_{d c}$ and two inner loops to control accurately the dq-axis currents $i_{d q}$ and $i_{q g}$. The independent control of $i_{q g}$ and $i_{d p}$ provides accurate control of reactive and active power control. To obtain the VOC scheme, the synchronous frame d-axis is aligned with the voltage vector of grid, therefore $\left(v_{d g}=v_{g}\right)$, and q-axis voltage $v_{g}$ is then equal to zero, from which the active and reactive power of the system can be obtained by

$$
P_{g}=\frac{3}{2} v_{d g} i_{d g}
$$

$Q_{g}=-\frac{3}{2} v_{d g} i_{q g}$
The q- axis reference current will be obtained from

$$
i_{q g}^{*}=-\frac{2}{3} \frac{Q_{g}^{*}}{v_{d g}}
$$

The DC reference voltage can be obtained from

$V_{d c}^{*}=\frac{\sqrt{6} V_{a i l}}{m_{a}}$

Where $V_{a l}$ is inverter line voltage and $m_{a}$ is modulation index. The real power on the AC side of the inverter with negligible losses in the inverter is

$$
P_{g}=\frac{3}{2} v_{d g} i_{d g}=v_{d c} i_{d c}
$$

\section{Simulation results}

The performance of non- salient PMSG WECS with zero d-axis current control of the generator-side converter and VOC of the grid side converter with SPWM and SVM techniques for both converters is presented. PMSG parameters are given in Table I. Generator side wave forms during start up are shown with both PWM techniques in Figure5(a) and 5(b). Generator torque starts rising from $\mathrm{t}=0.4 \mathrm{sec}$ and reaches the rated value $(1 \mathrm{pu})$ at $\mathrm{t}=1.4$ sec.

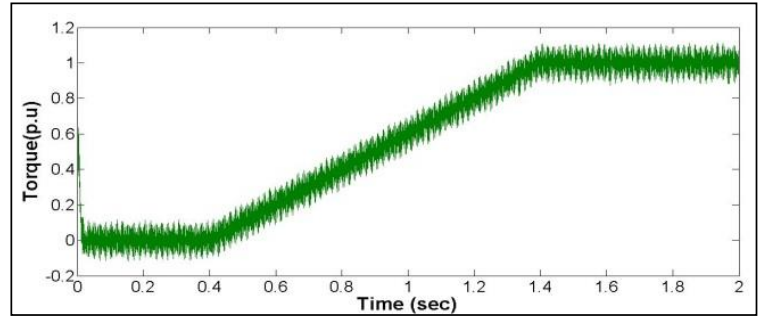

Fig. 5: (A) Generator Torque Waveform during Start up with SPWM for Generator Side Converter.

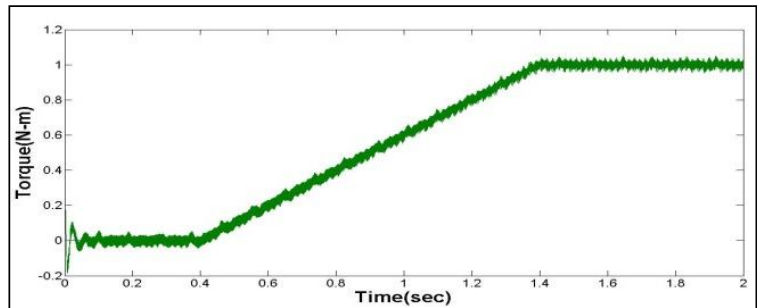

Fig. 5: (B) Generator Torque Waveform during Start up with SVM for the Generator Side Converter.

As the generator is controlled by ZDC technique, the d-axis stator current $i_{d s}$ is kept at zero. The stator current along q-axis $i_{q s}$ is proportional to the torque of the generator $\mathrm{T}$. The two currents $i_{d s}$ and $i_{q s}$ are in the synchronous frame of rotor flux and DC values in steady state are shown in Figure 6(a) and 6(b).From the results it is clear that, the ripple in $i_{q s}$ is less with SVM when compared to SPWM 


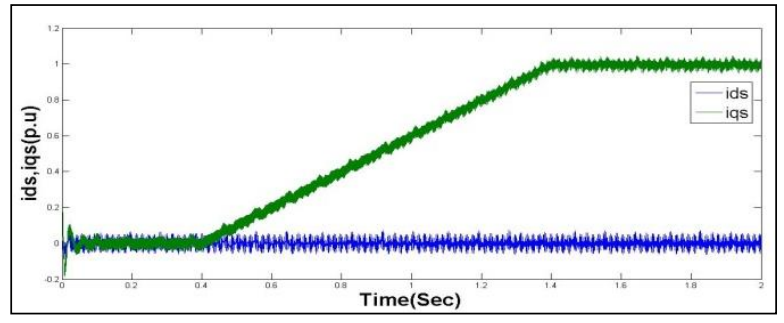

Fig. 6: (A) Generator D and Q Axis Currents with SPWM for the Generator Side Converter.

The phase a current of the generator $i_{a s}$, is shown in the Figure7. Its amplitude is proportional to $i_{q s}$ as $i_{d s}=0$. the amplitude of the current increases with $i_{q s}$.

Figure 8 shows the DC voltage $v_{d c}$, which is controlled by the grid side converter kept at its reference value of $2.15 \mathrm{pu}$ during the transient and as well as in steady state.

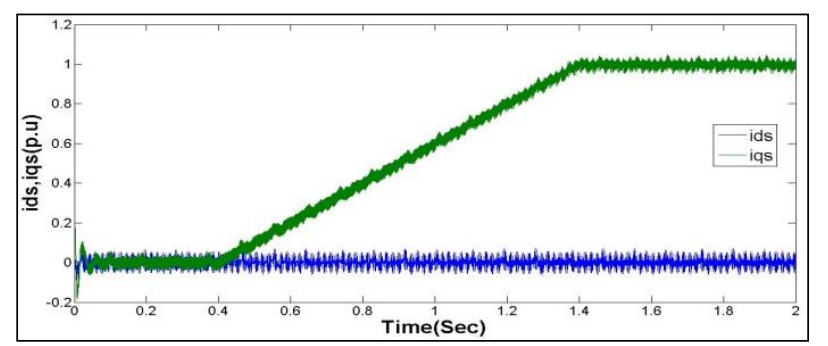

Fig. 6: (B) Generator D and Q Axis Currents with SVM for the Generator Side Converter.

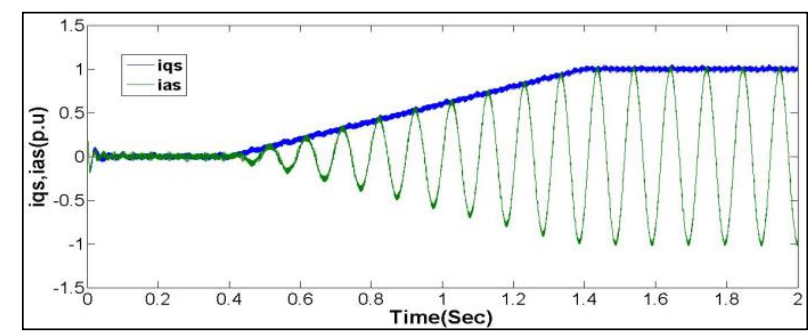

Fig. 7: (A) Generator A Phase Current with SPWM for the Generator Side Converter.

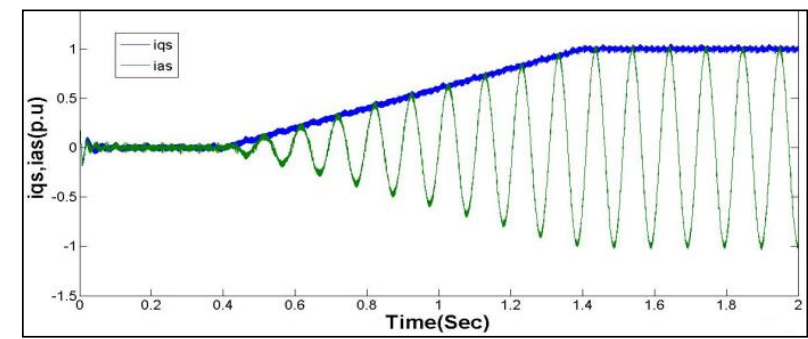

Fig. 7: (B) Generator A Phase Current with SVM for the Generator Side Converter.

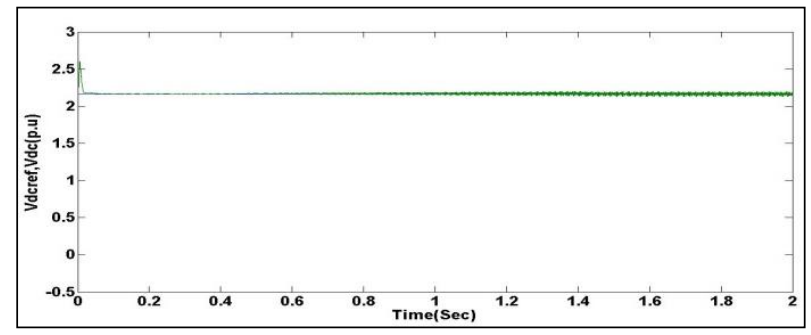

Fig. 8: (A) DC Link Voltage in P. U. with SPWM for the Generator Side Converter.

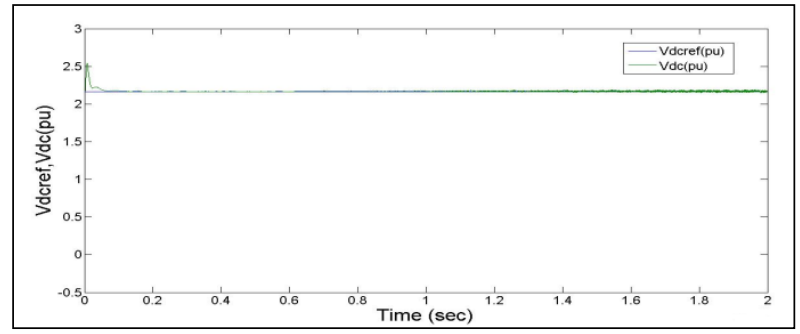

Fig. 8: (B) DC Link Voltage in P. U. with SVM for the Generator Side Converter.

The reactive power $Q_{g}$ on the grid side, is kept at zero to achieve unity power factor operation by the controller. The grid active power $P_{g}$ is negative value which is shown in Figure9, indicating that the power is flowing from the inverter to grid.

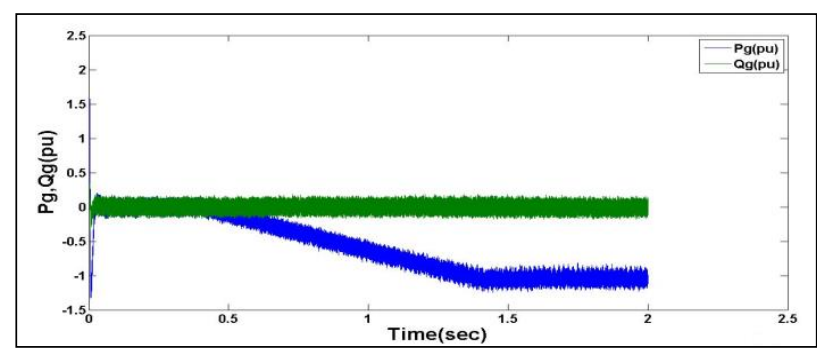

Fig. 9: (A) Active Power and Reactive Power on the Grid Side with SPWM for the Grid Side Converter.

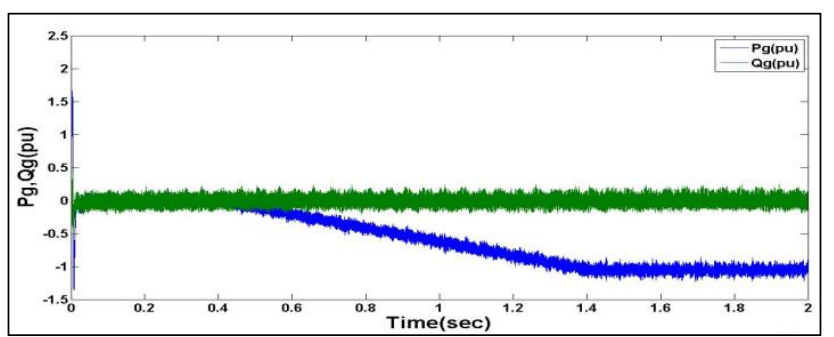

Fig. 9: (B) Active Power and Reactive Power on the Grid Side with SVM for the Grid Side Converter.

The power factor of the grid is maintained at unity by the controller as reactive power is kept at zero. The waveform the power factor is shown is Figure10.

THD of the grid current with both SPWM and SVM techniques is shown in the Figure11; from the waveforms it is clear that, THD in the grid current is less with SVM when compared to SPWM.

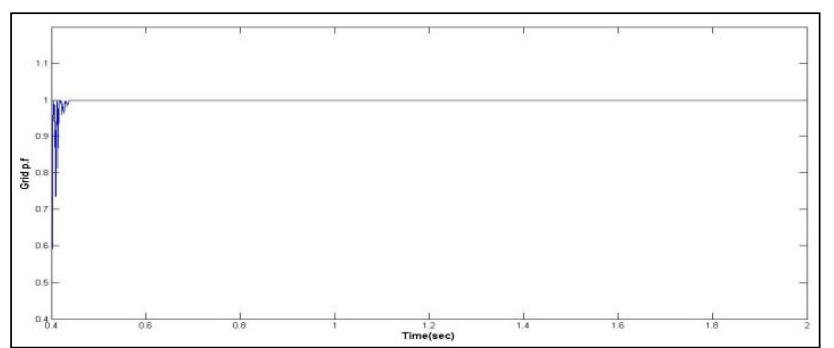

Fig. 10: (A) Grid P. F with SPWM for the Grid Side Converter.

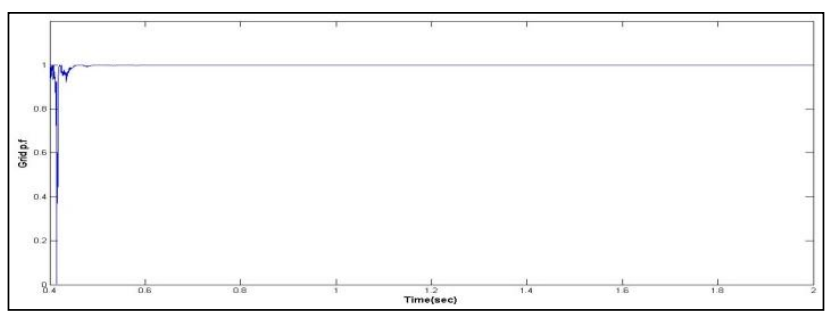

Fig. 10: (B) Grid P. F with SVM for the Grid Side Converter. 


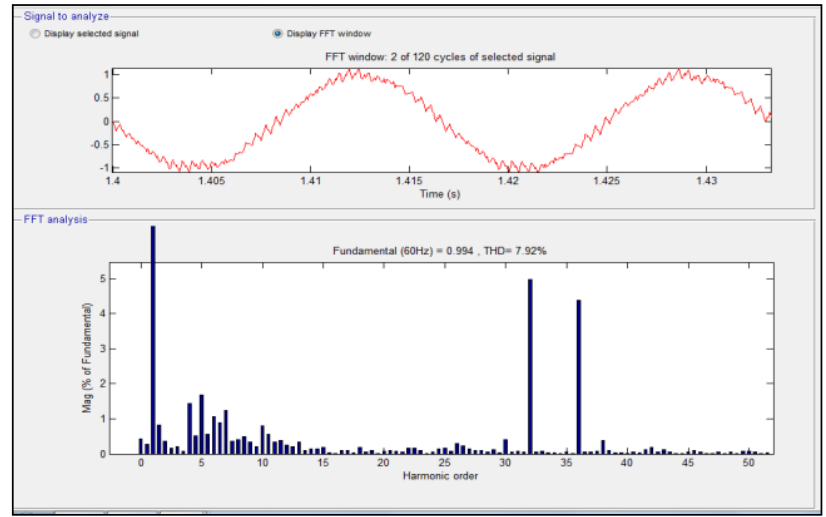

Fig. 11: (A) THD of Grid Current with SPWM for the Grid Side Converter (Inverter).

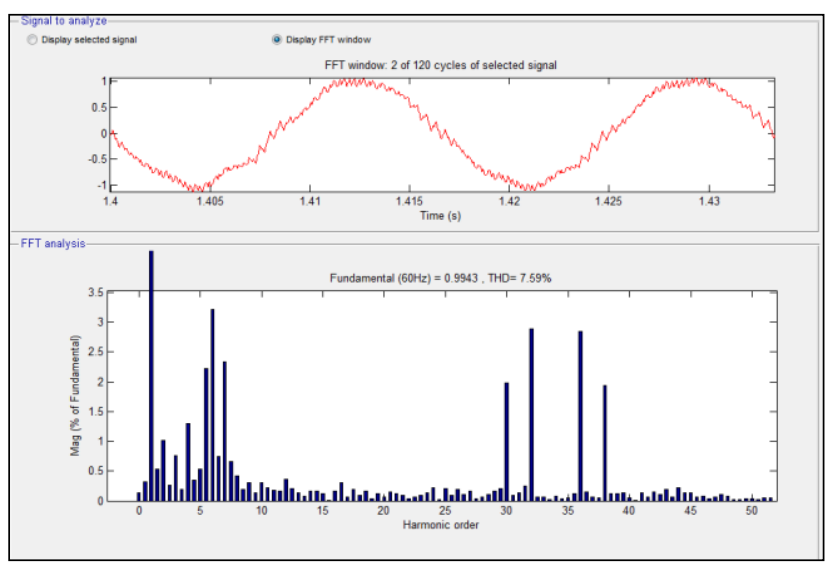

Fig. 11: (B) THD of Grid Current with SVM for the Grid Side Converter (Inverter).

\section{Conclusion}

In this paper, performance of PMSG based WECS with back-to back PWM converters is analysed. Voltage oriented control (VOC) is used for grid-connected converter along with SPWM and SVM schemes. The generator is controlled by using zero d- axis current (ZDC) control scheme along with optimal torque control (OTC). The control strategy is developed for the generator operation which is optimized while obtaining the maximum power from wind. The control system of the generator decouples the q-axis and d-axis stator current by using vector control for the converter on generator-side. From the results, the performance of PMSG based WECS is superior when SVM is used for both the converters when compared to SPWM scheme.

\section{References}

[1] Bin Wu, Yongqiang Lang, Navid Zargari, Samir Kouroi. Power Conversion and control of Wind Energy Systems. Wiley, 2011. https://doi.org/10.1002/9781118029008.

[2] Carrasco J M. L. G. Franquelo, J. T. Bialasiewicz, S. S. Member, E. Galván, R. C. P. R. C. P. Guisado, M. Ángeles, M. M. Prats, J. I. León, N. Moreno-alfonso, E. Galvan, M. Angeles, and J. I. Leon(2006). Power Electronic Systems for the Grid Integration of Renewable Energy Sources: A Survey. IEEE Transactions on Industrial Electronics, 53(4), 1002-1016. https://doi.org/10.1109/TIE.2006.878356.

[3] Chen Z, J. M. Guerrero, F. Blaabjerg, and S. Member (2009). A Review of the State of the Art of Power Electronics for Wind Turbines. IEEE Transactions on Power Electronics, 24(8), 1859-1875. https://doi.org/10.1109/TPEL.2009.2017082.

[4] Chen Z and E. Spooner (1998). Wind Turbine Power Converters : a Comparative Study. Proceedings of IET 7th International Conference on Power Electronics and Variable Speed Drives, 456, 21-23. https://doi.org/10.1049/cp:19980572.

[5] Chinchilla M, S. Arnaltes, and J. C. Burgos(2006) .Control of Permanent-Magnet Generators Applied to Variable-Speed Wind-
Energy Systems Connected to the Grid. IEEE Transactions on En-

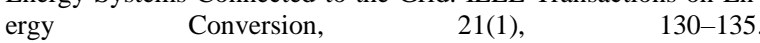
https://doi.org/10.1109/TEC.2005.853735.

[6] Dincer I (2000) .Renewable energy and sustainable development: a crucial review. Renewable and Sustainable Energy Reviews, 4(2), 157-175. https://doi.org/10.1016/S1364-0321(99)00011-8.

[7] Huang K H K, S. H. S. Huang, F. S. F. She, B. L. B. Luo, and L. C. L. Cai(2008).A control strategy for direct-drive permanent-magnet wind-power generator using back-to-back PWM converter.Proceedings of International Conference on Electrical Machines and Systems, 2283-2288.

[8] Sai I and B. Kumar (2016). Direct control technique for PMSG based Variable speed Wind Applications. Proceedings of International Conference on Electrical, Electronics, and Optimization Techniques (ICEEOT), 2543-2548.

[9] Shubham Khandelwal and Ketan P Detroja(2017). Controlled Power Point Tracking for Autonomous Operation of PMSG based Wind Energy Conversion System. Proceedings of Indian Control Conference (ICC), https://doi.org/10.1109/INDIANCC.2017.7846478.

[10] Sooraj Suresh Kumar,K Jayanthi and N Senthil Kumar(2016). Maximum Power Point Tracking For a PMSG Based Variable Speed Wind Energy Conversion System using Optimal Torque Control. Proceedings of IEEE International Conf. on Advanced Communication Control and Computing Technologies (ICACCCT), 347-352.

[11] Venkata Yaramasu, B. Wu, P. C. Sen, S. Kouro, and M. Narimani(2015).High-Power Wind Energy Conversion Systems : Stateof-the-Art and Emerging Technologies.Proceedings of IEEE,103(5), 740-788. https://doi.org/10.1109/JPROC.2014.2378692. 